\title{
UFSC
}

\section{PROJETO SÁBADO NO CAMPUS: ESPORTES ADAPTADOS E O GOALBALL NA FORMAÇÃO ACADÊMICA}

Originais recebidos em: 25/08/2010

Aceito para publicação em: 13/08/2011

Luciano Lazzaris Fernandes Universidade Federal de Santa Catarina lucianolazzarisfernandes@hotmai.com

Luiz Alberto Rodrigues Universidade Federal de Santa Catarina luizalbertorodrigues@gmail.com

Mariana Pereira Vasconcelos Universidade Federal de Santa Catarina maricanhota@gmail.com

Roger Lima Scherer

Universidade Federal de Santa Catarina rogerscherer@gmail.com

\section{Resumo}

O goalball no Projeto Sábado no Campus: Esportes Adaptados vem sendo desenvolvido desde 1996. A modalidade busca proporcionar às pessoas com deficiência visual uma prática paradesportiva com o intuito de melhorar sua qualidade de vida, além de propiciar melhor socialização. A comunidade acadêmica tem a oportunidade de vivenciar a tríade ensino, pesquisa e extensão com as pessoas com deficiência. O objetivo deste estudo é relatar como a modalidade goalball, desenvolvida no Projeto Sábado no Campus: Esportes Adaptados, tem influenciado na formação acadêmica de seus bolsistas. Essa modalidade ocorre três vezes por semana com duração de três horas diárias, às terças e quintas-feiras e aos sábados, sendo oferecida às pessoas da comunidade com deficiência visual. Além de oportunizar uma prática paradesportiva a esta população, a modalidade goalball no projeto ainda busca propiciar à comunidade acadêmica uma extensão de sua formação em sala de aula, oportunizando reflexão e desenvolvimento de sua práxis, além possibilitar a iniciação científica através das situações-problemas que surgem no dia a dia do projeto. Sendo assim, o projeto é extremamente importante para fortalecer cada vez mais a tríade ensino, pesquisa e extensão na formação acadêmica dos graduandos em Educação Física.

Palavras-chave: Goalball. Projeto de extensão. Esportes adaptados. Formação acadêmica.

\section{SATURDAY ON CAMPUS PROJECT: ADAPTED SPORTS AND GOALBALL IN THE UNDERGRADUATE ACADEMIC}

\section{Abstract}

Goalball in the "Saturday on Campus Project: Adapted Sports" has been developed since 1996. The modality seeks to make parasports practice available to people with visual impairments in order to improve their quality of life and stimulate better socialization. The academic community thus has the opportunity to experience a triad of teaching, research and extension in conjunction with disabled people. The objective of this study is to report on how the Goalball developed in the "Saturday on Campus Project: Adapted Sports" has influenced the education of undergraduate students. The practice of parasport is offered to the visually impaired community three times a week on Tuesdays, Thursdays and Saturdays, and lasts three hours per day. Apart from giving this community the opportunity to practice parasport, the Goalball mode in the project also seeks to provide the 
academic community with an extension to their training in the classroom, creating opportunities for reflection on, and development of, their practice, in addition to opening up the possibility of scientific initiatives arising from the problem situations that are encountered in the everyday life of the project. Therefore, the project is vital to a steady strengthening of the teaching, research and extension triad practiced by undergraduate students in physical education.

Keywords: Goalball. Community services project. Adapted sports. Undergraduate academic.

\section{CONSIDERAÇÕES INICIAIS}

Ciente da importância em promover a participação das pessoas com deficiência em práticas esportivas, o Centro de Desportos da Universidade Federal de Santa Catarina, através de um de seus docentes, idealizou em 1996 um projeto de extensão intitulado "Sábado no Campus: Esportes Adaptados".

Esse projeto tinha como intuito proporcionar a inserção das pessoas com deficiência na prática paradesportiva, oportunizando a socialização, além da melhora de sua qualidade de vida através de uma prática de lazer. Dessa iniciativa, a comunidade acadêmica do Centro de Desportos teve a oportunidade de desenvolver projetos de pesquisas e procedimentos didático-pedagógicos para o ensino e treinamento do paradesporto.

No Brasil, até o Censo Demográfico de 2000, a população das pessoas com deficiência estava estimada em 10\%. Através do Censo de 2000, esse índice passou para $15 \%$, totalizando 24,5 milhões de brasileiros. Desse número, aproximadamente 16,5 milhões são de pessoas com deficiência visual (IBGE, 2009).

O projeto inicialmente atendia às pessoas com deficiência visual que participavam da modalidade goalball. Não havia materiais adequados e nem conhecimento mais detalhado das regras da modalidade. Com o passar do tempo, o projeto adquiriu materiais adequados para o desenvolvimento desta atividade, além de estender suas atividades a outros segmentos de pessoas com deficiência e a outras modalidades paradesportivas, tais como natação, tênis sobre rodas, basquete sobre rodas, bocha paraolímpica, entre outras.

Segundo Nascimento e Mourato (2006, p. 10),

O goalball é uma modalidade esportiva desenvolvida especificamente para pessoas com deficiência visual. É baseado nas percepções auditivas e táteis, como também na orientação espacial. Caracteriza-se como uma atividade dinâmica, interessante e especial. São três jogadores em cada equipe, que lançam a bola, rolando no piso da quadra, para tentar fazer o gol. A outra 
equipe tenta impedir o gol com os três jogadores deitando-se no piso para realizar a defesa da bola lançada pelo adversário e, assim, a disputa segue em duas etapas; vence o jogo a equipe que conseguir o maior número de gols. $\mathrm{O}$ silêncio dos praticantes e espectadores é extremamente importante para o bom andamento da partida. $\mathrm{O}$ controle e a aplicação das regras são assegurados por uma equipe de arbitragem, composta por dois árbitros principais, mesários e juízes de linhas.

Essa modalidade foi idealizada após a segunda guerra mundial, em 1946, pelo austríaco Hanz Lorenzen e o alemão Sett Reidle com a finalidade de reabilitação dos veteranos de guerra; porém, com o decorrer dos anos, tomou proporções significativas até ser incluída como modalidade de alto rendimento nas paraolimpíadas (IBSA, 2009).

No Brasil há duas grandes vertentes apontadas para a chegada da modalidade. Uma aponta que o professor Steven Dubner trouxe a primeira bola de goalball para o país em 1985, iniciando essa modalidade no Clube de Apoio ao Deficiente Visual (CADEVI), em São Paulo; outra versão defende que, após o Mundial da Holanda, em 1986, o professor Mário Sérgio Fontes retornou com as bolas e regras oficiais dessa modalidade. O primeiro campeonato nacional foi disputado em 1987 (MATARUNA et al., 2005; CBDC, 2009).

As pessoas com deficiência visual possuem uma limitação sensorial que poderá levar a um comprometimento de seu desenvolvimento motor, afetivo, social e cognitivo. Todas as pessoas com deficiência visual podem participar da modalidade de goalball. Durante o jogo, segundo a Internetional Blind Sports Federation (IBSA), independente da classificação dos atletas, todos são obrigados a utilizar um tampão oftalmológico e vendas sobre os olhos, para ficarem vendados igualmente. Essa classificação esportiva é feita através do grau de comprometimento visual, o qual é subdividido em três categorias (CBDC, 2009; IBSA, 2009):

B1: de nenhuma percepção luminosa em ambos os olhos até a percepção de luz; porém, incapaz de reconhecer o formato de uma mão a qualquer distância ou direção.

B2: da capacidade de reconhecer a forma de uma mão à acuidade visual de 2/60 e/ou campo visual inferior a 5 graus.

B3: da acuidade visual de 2/60 à acuidade visual de 6/60 e/ou campo visual de mais de 5 graus até 20 graus. 
A prática paradesportiva vem crescendo no decorrer dos anos devido à conscientização maior dos praticantes e da sociedade, que busca adaptar e melhorar a acessibilidade aos locais destinados à prática deste esporte.

Os resultados apresentados nas últimas edições das competições internacionais, entre elas as Paraolimpíadas e os Jogos Parapan-Americanos, mostraram o crescimento do desporto adaptado brasileiro. Essa constatação está estritamente relacionada com os avanços científicos nessa área do conhecimento da Educação Física e com projetos desenvolvidos nas universidades junto a esta população. A universidade tem como objetivo básico produzir e disseminar o conhecimento e o faz através do ensino, da pesquisa e da extensão.

Assim, o presente estudo tem como objetivo relatar como a modalidade goalball, oferecida em uma dessas funções, extensão universitária, e desenvolvida no Projeto Sábado no Campus: Esportes Adaptados, tem influenciado na formação acadêmica de seus bolsistas.

\section{MATERIAL E MÉTODOS}

O goalball no Projeto Sábado no Campus: Esportes Adaptados iniciou com dez praticantes, no campo de grama do Centro de Desportos (CDS) da UFSC, sem nenhum material adequado à prática paradesportiva; porém, com o decorrer dos anos, materiais adequados à prática foram adquiridos, assim como um local apropriado para a realização dessa atividade.

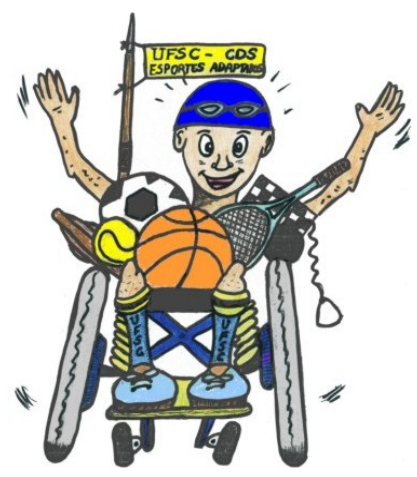

Figura 1: Logo Projeto Sábado no Campus: Esportes Adaptados Fonte: Projeto Sábado no Campus: Esportes Adaptados (1996). 
Nos dias atuais, a modalidade é desenvolvida nas instalações do CDS/UFSC três vezes por semana, com cerca de três horas diárias de duração, e conta com a participação de doze alunos/atletas, entre homens e mulheres, que participam dos treinamentos e competições estaduais, regionais, nacionais e internacionais.

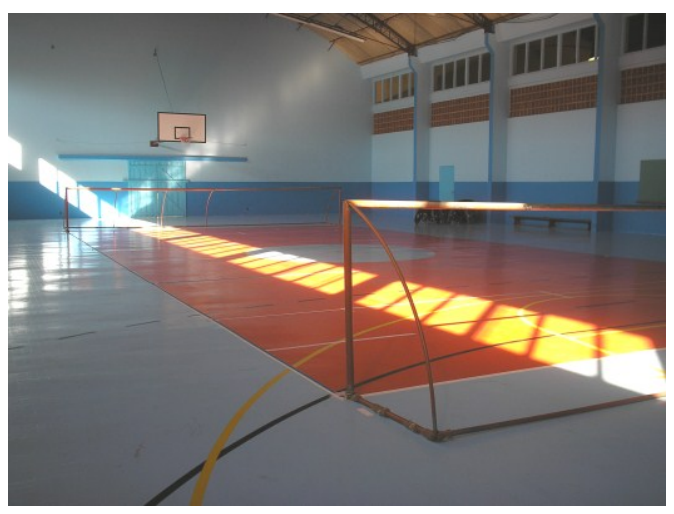

Figura 2: Ginásio de treinamento (CDS/UFSC Ginásio 2)

Fonte: Projeto Sábado no Campus: Esportes Adaptados (2008).

Os treinamentos são divididos em três momentos: físico, técnico e tático. A preparação física dos atletas é realizada na pista de atletismo do CDS/UFSC. Nessa preparação, são realizadas atividades que busquem o desenvolvimento de algumas capacidades e habilidades físicas necessárias para os atletas de goalball. O treinamento é planejado anualmente e é dividido em macrociclos, mesociclos, microciclos e unidades de treinamento.

As capacidades e habilidades necessárias para a prática são: resistência aeróbia e anaeróbia, flexibilidade, coordenação, orientação espacial, lateralidade, força, potência, direcionalidade, agilidade, tempo de reação, percepção auditiva e fortalecimento muscular.

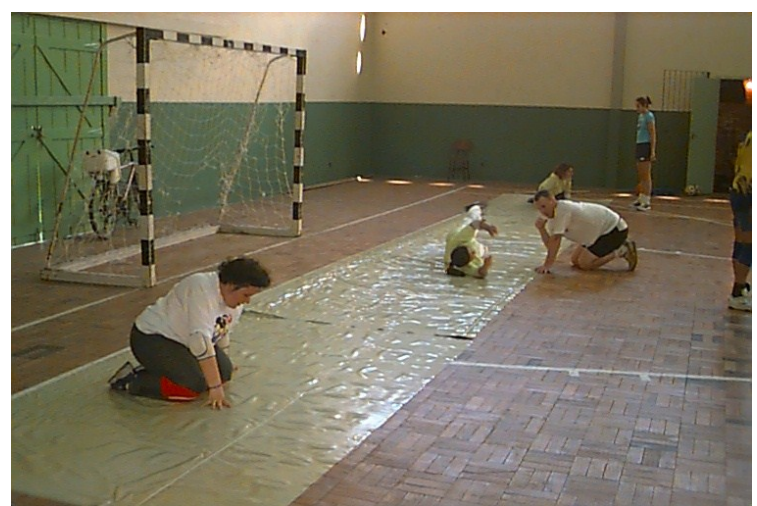

Figura 3: Alunos realizando deslocamentos

Fonte: Projeto Sábado no Campus: Esportes Adaptados (2001). 
A preparação técnica dos atletas é realizada no ginásio dois do CDS/UFSC devido à melhor qualidade do piso, pois, como os atletas se deslocam no chão utilizando seu corpo para interceptar a bola, o piso deve ser adequado para os atletas deslizarem sobre ele. Nesse momento, são realizadas atividades de orientação espacial, deslocamento, tempo de reação, direcionalidade, técnicas de defesa, passe e ataque, posicionamento de expectativa e contraataque.

A preparação tática também é realizada no ginásio dois do CDS/UFSC e são realizadas atividades que busquem aprimorar o sistema tático defensivo e ofensivo, e a prática de simulações de situações de jogo.

As atividades são praticadas por alunos/atletas com deficiência visual na faixa etária de 17 a 58 anos, homens e mulheres. Eles possuem entre baixa visão e cegueira, desta forma, a equipe é composta por atletas de todas as classes esportivas (B1, B2 e B3). Há atletas que foram trazidos ao esporte recentemente e outros que fazem parte da equipe desde a criação da atividade, há 14 anos, percebendo, vivenciando e relatando sobre as mudanças e avanços da modalidade.

O projeto é desenvolvido por um coordenador, três bolsistas de Educação Física, dois professores de Educação Física voluntários e um psicólogo voluntário. Esse grupo de profissionais, acadêmicos e atletas participam de competições estaduais, regionais e internacionais, organizadas pela Federação Catarinense de Desporto para Cegos e Baixa Visão (FECADESC), Fundação Catarinense de Esportes (FESPORTE), Confederação Brasileira de Desporto para Cegos (CBDC), Comitê Paraolímpico Brasileiro (CPB) e International Paralympic Committee (IPC).

\section{RESULTADOS E ANÁLISE}

Quando o goalball iniciou no projeto, em 1996, os professores e alunos não tinham uma referência para desenvolver essa modalidade por ser desconhecida por um segmento da população que participava pouco de atividades paradesportivas devido à falta de acessibilidade e oportunidade. Entretanto, o grupo idealizava desenvolver e fomentar o paradesporto para as pessoas com deficiência visual.

Através de projetos, foram adquiridos materiais adequados à prática; também realizouse uma formação mais específica para a modalidade em si. Após 2001, principalmente, 
quando houve a participação no primeiro campeonato da equipe nessa modalidade, os professores, os acadêmicos e os atletas sentiram a necessidade de melhorar a preparação em virtude dos objetivos almejados por todos. Sendo assim, os bolsistas que se identificavam com o projeto e a modalidade buscaram, através de sua formação nas disciplinas do curso de graduação em Educação Física, identificar pontos positivos para o desenvolvimento da atividade.

Diferente das modalidades convencionais como o basquetebol, o handebol, o voleibol e o futebol, o goalball não é oferecido aos acadêmicos como disciplina na graduação em Educação Física, e os acadêmicos acabam conhecendo essa modalidade rapidamente nas disciplinas adaptadas da área e/ou teoria e metodologia dos esportes adaptados.

Os acadêmicos do projeto possuem a oportunidade de vislumbrarem os sistemas tático e técnico, buscando ver as adequações para o goalball e a possibilidade de utilizar o atletismo como base para a preparação física dos atletas.

É necessário buscar conhecimento através de disciplinas como treinamento esportivo, cinesiologia e medidas e avaliações para organizar a periodização e mensurar os resultados alcançados ao longo dos anos. Anatomia, adaptações orgânicas e condicionamento físico são disciplinas importantes para identificar a necessidade do trabalho individualizado em cada grupamento muscular, ossos ou articulações ou para verificar as possibilidades de ganhos nos sistemas cardiorrespiratórios, de potência, ou para manipulação correta de algum suplemento alimentar.

A participação em projetos de extensão como esse, desenvolvido para as pessoas com deficiência visual no CDS/UFSC, é de extrema importância para auxiliar o acadêmico a vivenciar a tríade ensino, pesquisa e extensão.

O acadêmico tem a oportunidade, durante sua participação na modalidade de goalball, de presenciar situações estudadas nas disciplinas e se deparar com situações-problema em que há uma necessidade de estudar e pesquisar quais seriam as melhores práticas a serem oferecidas para solucionar tais problemas evidenciados.

Dessa forma, o projeto de extensão não irá apenas oportunizar a vivência da comunidade acadêmica ao colocar em prática situações aprendidas na sala de aula, mas iniciará, de forma gradual, o interesse do acadêmico, mostrando-lhe a importância de um professor-pesquisador, que busca constantemente formas e subsídios de melhorar sua práxis. 
Com esse olhar mais específico para o projeto e para o goalball em si, durante o decorrer dos anos, a modalidade deixou de ser apenas um momento prazeroso de lazer que melhora a qualidade de vida e passou também a ser uma oportunidade de profissionalização e uma possibilidade de participar de seleções que representam a cidade de Florianópolis, o estado de Santa Catarina e até mesmo a Seleção Brasileira dessa modalidade.

Durante os anos, houve uma progressão tanto dos alunos/atletas em sua qualidade de vida, em aspectos físicos, sociais, psicológicos e afetivos, quanto da comunidade acadêmica que atuou direto com essa população, na tríade ensino, pesquisa e extensão; assim, o projeto percebeu e melhorou o desenvolvimento da modalidade para com seus alunos/atletas em nível estadual e até nacional.

No decorrer desses anos, os alunos/atletas e os acadêmicos do projeto participaram de campeonatos estaduais e foram campeões em todas as edições que ocorreu a modalidade nos Jogos Paradesportivos de Santa Catarina (PARAJASC), organizados pela FESPORTE, e no Campeonato Estadual de Goalball nos naipes masculino e feminino, organizado pela FECADESC.

Com participação ativa nos campeonatos regionais da CBDC (região Sul), conquistaram resultados positivos em alguns anos, incluindo o primeiro lugar em 2004 na categoria feminino.

Nos campeonatos nacionais organizados pela CBDC, a equipe obteve o segundo lugar na série B, em 2003, na categoria masculino, e desde 2004 vem se mantendo nas posições intermediarias da série A, na qual apenas as 12 melhores equipes do Brasil participam. Atualmente, apenas no naipe masculino, há cerca de 50 equipes na modalidade de goalball em nosso país.

Com os bons resultados, fruto do trabalho de todos os integrantes da equipe, tanto acadêmicos como alunos/atletas participaram de seleções estaduais nos campeonatos nacionais estudantis, nos anos de 2008 e 2009, organizados pelo Comitê Paraolímpico Brasileiro (CPB), e participaram da seleção estadual no campeonato internacional organizado pela FECADESC em 2006.

Anteriormente (em 2003), duas atletas do projeto foram convocadas para a seleção brasileira e participaram do Mundial de goalball em Quebec, no Canadá. A seleção conquistou a medalha de prata e a inédita vaga para as Paraolímpiadas de Atenas, em 2004. 
Em 2008, foi a vez de um atleta ser convocado para representar o Brasil na primeira participação nacional nos Jogos Paraolímpicos em Beijin, na China.

O projeto Sábado no Campus: Esportes Adaptados, que até o ano de 2005 teve a única equipe de goalball do estado de Santa Catarina, oportuniza cursos e palestras a seus acadêmicos e a profissionais de outras cidades, buscando cada vez mais fomentar o goalball e mostrar a importância da prática paradesportiva para as pessoas com deficiência visual em Santa Catarina. Hoje, o estado conta com dois campeonatos estaduais, organizados e estruturados pela FECADESC e pela FESPORTE, e com um quadro de arbitragem e seis equipes, entre as quais algumas possuem atletas em nível de seleção brasileira.

A atuação de alguns acadêmicos no projeto foi de vital importância para seu estreitamento no campo de atuação dentro da Educação Física, e, dessa formação direcionada para o paradesporto, criou-se uma coordenadoria da modalidade de goalball na FECADESC a partir de 2006, que oportunizou a formação de árbitros nessa modalidade, que atuam em campeonatos estaduais, regionais e nacionais.

Os acadêmicos participantes da modalidade de goalball buscaram, no decorrer dos anos, realizar pesquisas, organizando e estruturando alguns trabalhos acadêmicos que foram apresentados e publicados em eventos locais, regionais, nacionais e internacionais, como: Semana da Educação Física; Semana de Ensino, Pesquisa e Extensão (SEPEX); Congresso Brasileiro de Extensão Universitária; Congresso Brasileiro de Atividade Motora Adaptada; Congresso Internacional de Treinamento Esportivo da Rede CENESP; Congresso Brasileiro de Atividade Física \& Saúde; Simpósio SESC de Atividade Motora Adaptada; Congresso Internacional de Educação Física (FIEP); International Symposium of Adapted Physical Activity, entre outros.

O reconhecimento dessa atividade de extensão está concentrado em forma de palestras e minicursos que os membros do projeto ministram em disciplinas de graduação na Educação Física da UFSC, em cursos na Universidade do Estado de Santa Catarina (UDESC), em eventos locais, como os Jogos Internos da Educação Física, e para pessoas com deficiência visual, sobre a modalidade de goalball.

\section{CONSIDERAÇÕES FINAIS}

A graduação é uma etapa da vida acadêmica dos profissionais ligados ao paradesporto. No curso de Educação Física, há um leque de oportunidades nas mais diversas áreas de 
atuação. Dessa forma, cabe ao graduando buscar, nessa etapa, usufruir ao máximo das possibilidades oferecidas para, no momento em que decidir seu campo de atuação, especializar-se para melhor práxis futura.

O projeto é um espaço importantíssimo para a inclusão social e melhora na qualidade de vida dessa população, assim como é um campo riquíssimo para o desenvolvimento de pesquisas, visto que fortifica o aprendizado, desenvolve uma consciência de professor/pesquisador e contribui diretamente nas atividades do projeto para com os atletas.

A modalidade de goalball no Projeto Sábado no Campus: Esportes Adaptados não é somente um campo de atuação como projeto de extensão, é também um potencial campo de pesquisa, pois a modalidade é relativamente nova comparada às modalidades convencionais; a população é distinta e especifica, possuindo suas limitações visuais, porém, podem apresentar um desenvolvimento motor normal se bem estimulado.

Dessa forma, o goalball e o projeto são fundamentais para os alunos/atletas, desde aqueles que a praticam por lazer até os que buscam a modalidade de forma mais séria e sistemática, além da importância para os acadêmicos que veem o projeto como uma oportunidade de vivenciar na prática situações discutidas em sala de aula e, a partir desses momentos, ter possibilidade de iniciar um processo de pesquisas acadêmicas tanto qualitativas quanto quantitativas.

\section{REFERÊNCIAS}

CONFEDERAÇÃO BRASILEIRA DE DEPORTOS PARA CEGOS(CBDC). Goalball. Disponível em: <http://www.cbdc.org.br>. Acesso em: 23 dez. 2009.

INSTITUTO BRASILEIRO DE GEOGRAFIA E ESTATÍSTICA (IBGE). Censo

Demográfico 2000. Disponível em:

$<$ http://www.ibge.gov.br/home/estatistica/populacao/censo2000/>. Acesso em: 23 dez. 2009.

INTERNATIONAL BLIND SPORTS FEDERATION (IBSA). Goalball. Disponível em:

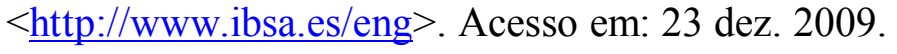

MATARUNA, Leonardo et al. Inclusão social: esportes para deficientes visuais. In: DA COSTA, L. Atlas do esporte no Brasil. Rio de Janeiro: Shape, 2005, p. 645-649.

NASCIMENTO, Dailton Freitas do; MOURATO, Marcio Pereira. Goalball: manual de orientação para professores de educação física. Brasília: Comitê Paraolímpico Brasileiro, 2006. 